\title{
Short-term Memory Comparison between Stunted and Non-Stunted Groups
}

\author{
Irma Suwandi Sadikin, ${ }^{1}$ Leonardo Lubis, ${ }^{2}$ Julistio T. B. Djais ${ }^{3}$ \\ ${ }^{1}$ Kebayoran Lama General Hospital South Jakarta, Indonesia, ${ }^{2}$ Department of Biomedical Sciences \\ Faculty of Medicine Universitas Padjadjaran Bandung, Indonesia, ${ }^{3}$ Departement of Child Health \\ Faculty of Medicine Universitas Padjadjaran/Dr. Hasan Sadikin General Hospital Bandung, \\ Indonesia
}

\begin{abstract}
Background: Long-term insufficient nutritional needs will directly impact on the development and maturation of brain function. Disruption of development and maturation process in the brain is associated with decreased cognitive abilities. Frequently, the effect of long-term nutritional insufficiency has also height deficits called stunting.This study aimed to compare the short-term memory between stunted and non-stunted groups.

Methods: A comparative study was conducted on 30 children in a non stunted group and 30 children in a stunted group. Children in both groups were selected from one of the elementary schools in Jatinangor using the simple random sampling method toward 3-5 for grade and 8-10 for age groups. The measurement of memory aspects for short-term memory used the Digit Span Test (forward and backward) and Simbol Modality Test.

Results: The collected data were in normal and not normal distribution because the statistical test used the independent-t test and Mann-Whitney. The mean memory score comparison between group 1 and group 2 on Digit Span Test Forward was 5.33:5.33 ( $\mathrm{p}=0.994)$, Digit Span test Backward was 2.73:2.60 ( $\mathrm{p}=0.440)$, and Symbol Modality Test was 20.90:19.60 ( $\mathrm{p}=0.347)$.

Conclusions: There is no significant difference in short-term memory between stunted and nonstunted groups, due to some confounding factors such as, environmental aspect, parent's education level, socioeconomic, and genetic factors.
\end{abstract}

Keywords: Cognitive development, short-term memory, stunted

\section{Introduction}

Malnutrition is a manifestation of insufficient intake of nutrition. Malnutrition is a common problem in developing countries even in the world. Children with severe malnutrition have more than an eight-fold greater risk of mortality and also gives long-term effects on cognitive and social development, physical work capacity, productivity and economic growth. ${ }^{1}$ Survivors of chilhood undernutrition frequently have deficits in height and weight that persist beyond adolescence into adulthood. ${ }^{1}$ One of the manifestations of chronic malnutrition is stunting. Stunting is low height for age proportion and based on growth chart is <-2SD. ${ }^{1}$ According to Riset Kesehatan Dasar (RISKESDAS) in 2010, the sites of the Ministry of Health in Indonesia show that $35.6 \%$ of children under five are stunted and it is still a major problem in indonesia. ${ }^{2}$

Stunting is associated with reduction of cognitive abilities in children. Long-term insufficienct nutritional intake will directly impact on the development and maturation of brain function. Disruption of development and maturation of the brain is associated with decreasing in cognitive abilities. ${ }^{3}$ Decreasing in cognitive abilities will impact on the child's learning process. Short-term memory is important for the learning process and formation of long-term memory. ${ }^{4}$

Therefore, the author is interested in examining the comparison of cognitive aspects especially for short-term memory between 
stunted and non- stunted groups in children aged 8-10 years.

\section{Methods}

The method used in this study was comparative study. This study was conducted in September 2015 and was approved by the Health Research Ethics Committee Faculty of Medicine, Universitas Padjadjaran. All participants were students from Karangmulya elementary school in Jatinangor, Sumedang district, West Java province, Indonesia. A total of 103 students from grade 3-5 were selected using the simple random sampling. The 103 students were then measured for their height. Based on the height measurement result, the total subjects obtained were 60 students. Next, they were divided into two groups, 30 students for the normal group and 30 students for the stunted group. The eligible participants ranged from 8 to 10 years of age, and were free from the exclusion criteria, such as children who had spinal abnormalities (such as scoliosis, kyphosis, lordosis), and children who slept less prior to the study; ${ }^{5}$ Children who consumed foods, beverages, and medications that contained caffeine infortyeight hours prior to the study (such as: tea, coffee, chocolate, energy drinks); ${ }^{6}$ Children who were diagnosed with thyroid disease; ${ }^{7}$ Children who had experienced anxiety that couldnot be appeased, and Children who were diagnosed with impaired vision, hearing, and extremely impaired motor function that could interfere the measurement process. Prior to the beginning of this study, parents were invited to attend the meeting in which the study procedures were explained thoroughly and informed written consent was obtained.

Furthermore, an thropometric measurements were performed to measure height, and adjust weight based on the age of the study subjects. Weight was recorded by using stepped measuring to the nearest 0.1 $\mathrm{kg}$ on the weighing scale. Height was recorded by using microtoise measuring to the nearest $0.1 \mathrm{~cm}$. Anthropometric data were used to calculate a height for-age Z-score (HAZ) by using the World Health Organization (WHO) growth reference data. Children with a $\mathrm{HAZ}<-2$ SD from the reference median were classified as stunted.

In order to assess short-term memory, the Digit Span Test Forward, Backward Digit Span Test, and Symbol Digit Modalities Test were used. The tests are components of the Wechsler memory scale (WMS) and the Wechsler intelligence scale which focused on working memory and selective attention. Digit span forward is considered to measure the atention aspect, Digit Span Backward is considered to measure the working memory/short-term memory. Span refers to the ability in holding an adequate amount of information in working memory. It refers to how much information can be held after a single presentation in correct serial order also required the additional processing components of mental manipulation numbers, internal visual scanning, and/or visuospatial processing. ${ }^{8}$

Numeric data were summarized from the score of short-term memory test (Digit Span Test Forward, Backward Digit Span Test, and Symbol Digit Modalities Test) and categorical data were from each group (group 1 for normal and group 2 for stunted). Differences in cognition scores across the stunted and normal groups were compared by using Independent sample t-tests for normal distribution data. The Mann-Whitney test for not normal distribution was $\alpha<0.05$ which was considered statistically significant. All analyses were performed by using statistic software.

\section{Results}

Furthermore, the characteristics of both groups showed, the Mean of Z-score for Non-

Table 1 Characteristics of Non-stunted/Normal group

\begin{tabular}{lccc}
\hline & Mean & Interval & Standard Deviation \\
\hline Age & 115 months & $98-127$ months & 9 \\
Weight & 26.17 & $20-40$ & 4.549 \\
Height & 128.99 & $119-145.6$ & 6.523 \\
BMI & 15.34 & $13-25$ & 2.712 \\
Z score height for age & -1.17 & $(-1.98)-0.8$ & 0.719 \\
\hline
\end{tabular}


Table 2 Characteristics of stunted group

\begin{tabular}{lccc}
\hline & Mean & Interval & Standard Deviation \\
\hline Age & 110 months & $96-126$ months & 12 \\
Weight & 21.77 & $17-27$ & 2.424 \\
Height & 118.27 & $108-126.9$ & 2.208 \\
BMI & 15.52 & $12.9-17.8$ & 1.135 \\
Z score height for age & -2.54 & $(-3.66)-(-2.02)$ & 0.389 \\
\hline
\end{tabular}

stunted group was -1.17 and mean of Z-score for stunted group was -2.54 (Table 1 and 2).

Moreover, results of the tests showed the mean memory score comparison between group 1 and group 2 on Digit Span test Forward $(\mathrm{p}=0.994)$, Digit Span test Backward $(\mathrm{p}=0.440)$, and Symbol Modality Test $(p=0.347)$ There was no significant difference in short-term memory scores by examination with the Digit Span Test Forward, Backward and Symbol Modality Test between the two groups (Figure $1)$.

\section{Discussion}

Measurement in this study refers to an examination that focuses on attention of examining the cognitive form. Attention is the taking possession of the mind, in clear and vivid form, of one out of what seem several simultaneously possible objects or trains thoughts. ${ }^{9}$ It implies withdrawal from some things in order to deal effectively with others.9 Heightened attention also paves the way for memory processes. Areas of the brain such as the posterior parietal neuron, limbic area, ascending reticular activating system (ARAS) and prefrontal area have an important role for these process. $^{9}$ The Symbol Digit Modalities Test performance is associated with increasing of brain activity in frontal and parietal areas involves in selective attention and working memory functions. ${ }^{10}$ Attention is divided into four categories such as focused attention, selective attention, sustained attention, switching or mental set shifting, and divided attention. The three examinations in this study included the examination of the type of selective attention. Selective attention refers to vigilance in monitoring information or ability

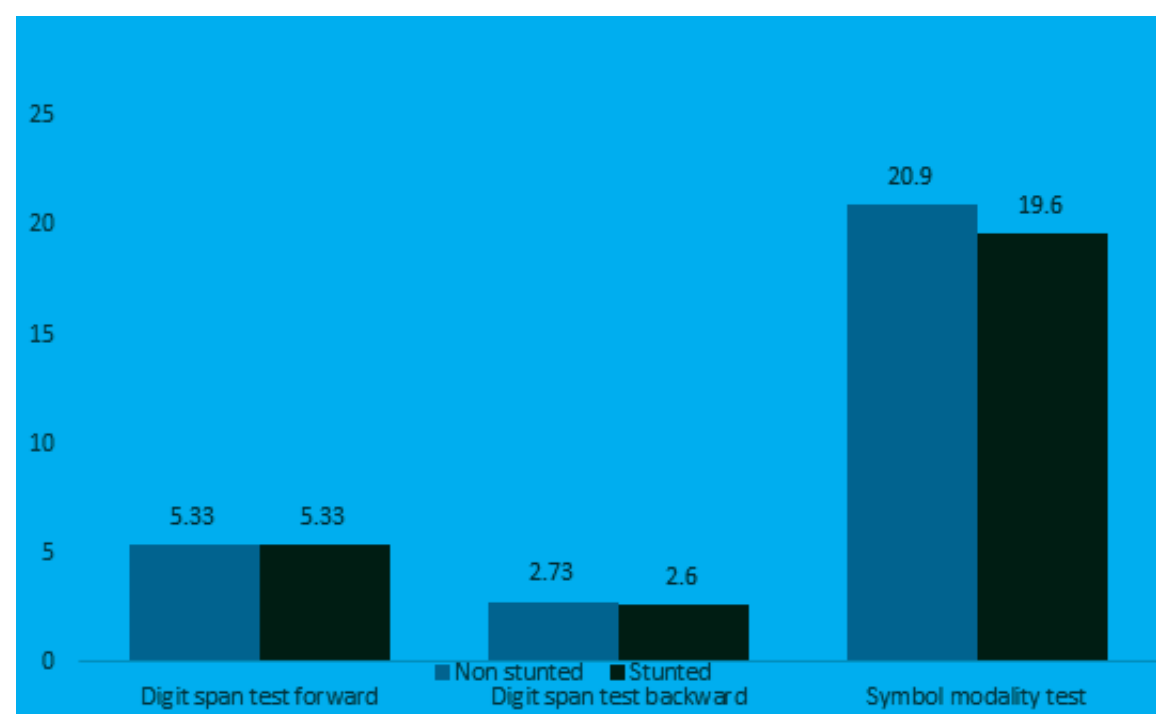

Figure 1 Comparison of Short-Term Memory between Stunted and Non Stunted Groups *p -value >0.05 (No Significant Difference) 
to maintain a cognitive set in the presence of background "noise" or distraction. ${ }^{9}$ This test can be influenced by several factors such as context, content and culture, and the linguistic factor also contributes to the result of the test. Therefore, this study was related to technical errors so that it showed no significant result.

Cognitive development is influenced by genectic, environment and nutrition in general. ${ }^{1}$ Long-term nutritional insufficiency can give impact on brain development especially on the cognitive aspect. However, the impact is not only on brain development but also on height deficits which can cause stunting. Therefore, stunting is associated with decreasing of cognitive development. The statement mentioned above is supported by a previous study, which stated that stunted children and children with chronic malnutrition are associated with decreasing of cognitive ability. Another previous study also stated that stunted children and children with chronic malnutrition are associated with decreasing of cognitive ability based on short-term memory test, retrieval ability, verbal fluency, selective attention, visuospatial abilities, verbal learning and memory.,11,12

Another study stated about the effect of undernutrion to cognitive ability using Intelligence Quotient (IQ). The result showed that undernourished children have low cognitive ability especially for the attention aspect, executive function, calculation, visuoperceptual ability, long term learning, and memory and intelligence. ${ }^{13}$ These statements supported the hypothesis of this study.

Furthermore, the result of this study was different from another study. This study result showed, stunted children and non-stunted children did not have a signifficant difference on cognitive ability especially for short-term memory. This difference could be due to other factors that could influence this result. Factors like mental ability from parents, education of parents, socioeconomic and environment can affect the cognitive development and nutritional status of children. ${ }^{14-17}$ There also will be a risk factor for occurence of malnutrition in children. These factors could possibly be non significant for the result, due to the characteristic of most subjects were low level of education and elementary and junior high school graduates, who live in rural areas. Moreover, the genetic factor also can contribute to the cognitive development and languange ability of someone. ${ }^{18-20}$ Generally, these factors will affect a child's growth and development process. However, it depends on the different stimulation and response which can affect a child's growth and development process.

Based on the statements above, the author has found facts which differ from the existing theories that there is no difference in shortterm memory between stunted children and non-stunted children. Nevertheless, there are many factors which can influence the cognitive and nutrional status of children such as, culture, mental ability of parents, child guidance, genetic variation, and past nutritional status (birth weight). In this study the environment al factor is not considered.

\section{References}

1. Kliegman RM, Behrman RE, Jenson HB. Nelson Textbook of Pediatric. $18^{\text {th }}$ ed. Philadelphia: Elsevier; 2007. p. 22-53.

2. DEPKES. STOP Generasi Stunting di Indonesia : Kementrian esehatan RI; 2011 [cited 201415 february]. Available from: http://gizi.depkes.go.id/stop-generasistunting-di-indonesia.

3. Kar BR, Rao SL, Chandramouli BA. Cognitive development in children with chronic protein energy malnutrition. Behav Brain Funct. 2008;4(1):31-43.

4. Papalia DE, Olds SW, Feldman RD. Human Development. 10th ed. New York: McGrawHill Companies; 2006. p. 5-522

5. Alhola P, Polo-Kantola P. Sleep deprivation: Impact on cognitive performance. Neuropsychiatr Dis Treat. 2007;3(5):55367.

6. Nobre AC, Rao A, Owen GN. L-theanine, a Natural Constituent in Tea, and Its Effect on Mental State. Asia Pac I Clin Nutr. 2008;17(1):167-68.

7. Wheeler SM, Willoughby KA, McAndrews MP, RovetJF. Hippocampal size and memory functioning in children and adolescents with congenital hypothyroidism. J Clin Endocrinol Metab 2011;96(9):1427-34.

8. Woods DL, Kishiyama MM, Yund EW, Herron TJ, Edwards B, Poliva O, et al. Improving digit span assessment of short-term verbal memory. J Clin Exp Neuropsychol. 2011;33(1):101-11.

9. Baron IS. Neuropsychological Evaluation of The Child. New York: Oxford University Press; 2004. p. 215-27.

10. Forn C, Belloch V, Bustamante JC, Garbin G, Parcet-Ibars MA, Sanjuan A, et al. A symbol digit modalities test version vuitable for functional MRI studies. Neurosci Lett. 2009;456(1):11-4. 
11. Crookston BT, Dearden KA, Alder SC, Porucznik CA, Stanford JB, Merrill RM, et al. Impact of early and concurrent stunting on cognition. Matern Child Nutr. 2011;7(4):397-409.

12. Sokolovic N, Selvam S, Srinivasan K, Thankachan P, Kurpad2 A, Thomas T. Catch-up growth does not associate with cognitive development in Indian school-age children. Eur J Clin Nutr. 2014;68(1):14-8.

13. Kesari KK, Handa R, Prasad R. Effect of undernutrition on cognitive development of children. Int J Food Sci Nutr. 2010;3(2):133-48.

14. Walker SP, Chang SM, Powell CA, Simonoff E. Early childhood stunting is associated with poor psychological functioning in late adolescence and effect are reduces by psychosocial stimulation. J Nutr. 2015;22(1):2464-79

15. Azis NRA, Muzakkir H. Faktor risiko gizi buruk pada anak balita. Journal of Pediatr. Nurs. 2014;1(2):63-9.

16. Puspitasari FD, Sudargo T, Gamayanti IL. Hubungan antara status gizi dan faktor sosiodemografi dengan kemampuan kognitif anak sekolah dasar di daerah endemis GAKI. JGI. 2011;1(34):52-60.

17. Warsito O, Khomsan A, Hernawati N, Anwar F. Relationship between nutritional status, psychosocial stimulation, and cognitive development in preschool children in Indonesia. Nutr Res Pract. 2012;6(5):4517.

18. Tucker-Drob EM, Briley DA. Continuity of genetic and environmental influences on cognition across the life span: a metaanalysis of longitudinal twin and adoption studies. Psychol Bull. 2014;140(4):94979.

19. Schady N. Parents' education, mothers' vocabulary, and cognitive development in early childhood: longitudinal evidence from Ecuador. Am J Public Health. 2011;101(12):2299-307.

20. Byrne B, Coventry WL, Olson RK, Samuelsson S, Corley R, Willcutt EG, et al. genetic and environmental influences on aspects of literacy and language in early childhood: continuity and change from preschool to grade 2. J Neurolinguistics. 2009;22(3):219-36. 